\title{
DETERMINATION OF ADSORPTION PERFORMANCE OF HYDROTHERMALLY SYNTHESIZED NANOCOMPOSITE
}

\author{
Hasan Sayğıl1 \\ Department of Petroleum and Natural Gas Engineering, Faculty of Engineering and Architecture, Batman \\ University, 72100 Batman, Turkey
}

\begin{abstract}
In this study, a novel nanocomposite was synthesized by a simple one-pot hydrothermal process and used as an adsorbent for the removal of methylene blue (MB) and methyl orange (MO) dyes from the aqueous medium. Overall findings from batch experiments demonstrated that the prepared nanocomposite material (Fe/GBHC) had good adsorption capacity for MB and MO. The maximum adsorption capacities of the $\mathrm{Fe} / \mathrm{GBHC}$ were observed to be $11 \mathrm{mg} / \mathrm{g}$ for $\mathrm{MB}$ and $8.9 \mathrm{mg} / \mathrm{g}$ for $\mathrm{MO}$ at neutral $\mathrm{pH}$ of the solutions and at $303 \mathrm{~K}$. To obtain the adsorption mechanism of the Fe/GBHC, the experiments of adsorption isotherms were researched. The adsorption isotherms of both dyes could be described by the Langmuir isotherm equation rather than the Freundlich isotherm equation, with a high correlation coefficient values. The results showed that the prepared Fe/GBHC material by the hydrothermal method could have potential application in the removal of organic dyes from waste water.
\end{abstract}

Key words: Hydrothermal synthesis, nanocomposite, adsorption performance, wastewater treatment

\section{Introduction}

Industrial wastewater pollution triggered by organic dyes has been recognized as a global concern. Depending on the statistics, approximately 70.000 tons of dyes are discharged into the water environment per year [1]. Methylene blue (MB) is a typical organic dye widely used in spinning and weaving, papermaking, printing and dyeing, medicine and other industries [2]. Methylene blue residual dyes in wastewater are characterized by their deep color, high permeability and strong alkalinity, which inhibit the photosynthesis of aquatic plants, cause the growth of cancer cells in animals, and disrupt ecosystem balance [3]. Methyl orange (MO) is a typical acid anionic monoazo dye. MO is one of the types of organic dyes used in the textile and printing industry. MO is commonly used in textiles, laboratory experiments and other commercial products. Excessive release of MO is highly damaging to the environment as MO and its decay products are toxic, carcinogenic and mutagenic to living beings [4].

The hydrothermal process is due to its many advantages, especially due to the simple, easy-to-use experimental device, more and more attention. The use of the hydrothermal process enables the formation of more stable condensed phases to achieve high yield and low energy consumption. Synthetic parameters such as temperature and time, $\mathrm{pH}$, precursor concentration, etc., are fundamental for the successful production of high-quality nanostructures [5].

*Corresponding author: Address: Faculty of Engineering and Architecture, Batman University, 72100 Batman, Turkey. E-mail address: hasan.saygili @ batman.edu.tr, Phone: +904882173770 
Several traditional methods have been reported, such as coagulation, ion-selective electrodes, biosorption, photodegradation, electrochemical oxidation, ozonation, reverse osmosis and adsorption to remove hazardous contaminants. Due to its low energy cost, environmental compatibility, and ease of use, adsorption has been suggested to be a convenient approach to removing trace impurities from an aqueous solution [6].

In the present work, Fe/GBHC nanocomposite with well adsorption properties was prepared for the first time for the removal of $\mathrm{MB}$ and MO. The main objective of the present study was to investigate the removal of different organic dyes by Fe/GBHC. Finally, the adsorption mechanism of organic dyes on Fe/GBHC was discussed.

\section{Materials and Method}

\subsection{Materials}

Iron (III) chloride $\left(\mathrm{FeCl}_{3}\right)$, Methylene Blue hydrate $\left(\mathrm{C}_{16} \mathrm{H}_{18} \mathrm{ClN}_{3} \mathrm{~S} \cdot \mathrm{xH}_{2} \mathrm{O}\right)$, Methyl orange $\left(\mathrm{C}_{14} \mathrm{H}_{14} \mathrm{~N}_{3} \mathrm{NaO}_{3} \mathrm{~S}\right)$ and ethanol $\left(\mathrm{C}_{2} \mathrm{H}_{5} \mathrm{OH}\right)$ were purchased from Sigma-Aldrich Co. All the aforementioned reagents were of analytical grade and used without further purification. Deionized water was used throughout this study. As a raw material for the nanocomposite, grape bagasse (GB) was collected from a local fruit juice and wine factory in the Republic of Turkey.

\subsection{Synthesis of Fe/GBHC}

Nanocomposite was prepared by the simple one-pot hydrothermal method [7]. $10 \mathrm{~g}$ GB were to $50 \mathrm{ml}$ of a solution of iron (III) chloride $(0.5 \mathrm{M})$ and mix homogeneously at room temperature (100 rpm/15 min). The resulting mixture was transferred to a $100 \mathrm{ml}$ Teflon-coated stainless steel autoclave and sealed immediately. The autoclave was heated at $200{ }^{\circ} \mathrm{C}$ for 1 hour and then naturally cooled to room temperature. The black solid was separated from the solution by vacuum filtration and dried in an oven at $105^{\circ} \mathrm{C}$ for 12 hours. Thereafter, the sample was calcined in a tube furnace equipped with a horizontal tube reactor made of stainless steel for $1 \mathrm{~h}$ at $600{ }^{\circ} \mathrm{C}$ in a nitrogen atmosphere $\left(\mathrm{N}_{2}\right)$. The system was cooled to room temperature. The resulting material was washed several times with ethanol and distilled water and dried at $60{ }^{\circ} \mathrm{C}$ for 5 hours. Here the resulting product is called Fe/GBHC.

\subsection{Adsorption capacity test}

Periodic adsorption experiments were performed in $100 \mathrm{ml}$. Erlenmeyer flask by adding $0.1 \mathrm{~g}$ of nanocomposite in $50 \mathrm{ml}$ of dye solutions with different starting concentrations $(20-300 \mathrm{mg} / \mathrm{L})$ with natural $\mathrm{pH}$ values (6.33 for $\mathrm{MB}, 6.30$ for $\mathrm{MO}$ ). The flasks were shaken in a thermostat water bath at $303 \mathrm{~K}$ and $150 \mathrm{rpm}$ for 24 hours. After adsorption reached equilibrium, the mixture was centrifuged and filtered with $0.45 \mathrm{~mm}$ nylon syringe filter and residual concentration of each dye was visualized using UV-visible (Perkin Elmer lambda 25) at $665 \mathrm{~nm}$ for MB and $464 \mathrm{~nm}$ for MO. Amounts dyes adsorbed in equilibrium $\left(\mathrm{q}_{\mathrm{e}}\right)$ were calculated according to formula (1): 
$q_{e}=\frac{\left(C_{0}-C_{e}\right) V}{m}$

where $\mathrm{q}_{\mathrm{e}}(\mathrm{mg} / \mathrm{g})$ is the amount of adsorbent adsorbed per gram, $\mathrm{C}_{\mathrm{o}}$ and $\mathrm{C}_{\mathrm{e}}(\mathrm{mg} / \mathrm{L})$ are the initial and equilibrium dye concentrations in the solution, $\mathrm{V}(\mathrm{L})$ is the initial volume, and $\mathrm{m}(\mathrm{g})$ is the mass of the sorbent.

To evaluate the equilibrium behavior, two isothermal models were used, namely Freundlich [8] and Langmuir [9]. The linear form of these models can be expressed mathematically by the following equations:

Freundlich isotherm: $\ln q_{e}=\ln K_{F}+\frac{1}{n_{F}} \ln C_{e}$

Langmuir isotherm: $\frac{C_{e}}{q_{e}}=\frac{1}{q_{m} b}+\frac{1}{q_{m}} C_{e}$

where $\mathrm{K}_{\mathrm{F}}(\mathrm{L} / \mathrm{g})$ and $1 / \mathrm{n}_{\mathrm{F}}$ are the Freundlich model constants indicating the capacity or surface heterogeneity of the adsorption process. $\mathrm{b}(\mathrm{L} / \mathrm{g})$ is the Langmuir constant, which represents the adsorption energy of the binding sites, and $\mathrm{q}_{\mathrm{m}}(\mathrm{mg} / \mathrm{g})$ is the maximum adsorption in the monolayer. The values of the isotherm parameters and the linear regression coefficients $\left(\mathrm{R}^{2}\right)$ are determined. The quality of experimental data adapted to adsorption isothermal models was evaluated using a higher $\mathrm{R}^{2}$ value.

\section{Results and Discussion}

In this work, the adsorption feature of nanocomposite was investigated by selecting $\mathrm{MB}$ and $\mathrm{MO}$ as adsorbates. In Figure 1 shows the adsorption isotherms of both dyes at $30{ }^{\circ} \mathrm{C}$ on $\mathrm{Fe} / \mathrm{GBHC}$. The experimental data were selected from the models of the Langmuir and Freindlich isotherms. The calculated constants of the two equations of the isotherm are shown in Table 1. A high value of the regression coefficient $\left(\mathrm{R}^{2}\right)$ was used to determine the most suitable isotherm. When comparing the values of $\mathrm{R}^{2}$, it was found that the Langmuir model was more favorable than the Freundlich model because of the higher values of $\mathrm{R}^{2}$ for the dyes $\mathrm{MB}$ and $\mathrm{MO}$, suggesting that a single-layered adsorption process took place on the surface of Fe/GBHC. The adsorption intensities $(1 / \mathrm{n})$ for both dyes are between 0 and 1 , which indicates suitable adsorption conditions. The maximum adsorption capacity of $\mathrm{Fe} / \mathrm{GBHC}$ for $\mathrm{MB}$ and $\mathrm{MO}$ was $11 \mathrm{mg} / \mathrm{g}$ and $8.9 \mathrm{mg} / \mathrm{g}$, respectively. Therefore, the composite tested in this study can be used as a promising adsorption material for removing dyes from aqueous solutions. To demonstrate the importance of the Fe/GBHC used in this work, the maximum adsorption capacities $\left(\mathrm{q}_{\mathrm{m}}\right)$ of Fe/GBHC were compared with various other adsorbents described in earlier work and listed in Table 2.

Table 1. Isotherm constants and correlation coefficients calculated for MB and MO dyes adsorption onto Fe/GBHC 


\begin{tabular}{llll}
\hline Isotherm & Parameters & \multicolumn{2}{c}{ Dyes } \\
\cline { 3 - 4 } & & $\boldsymbol{M} \boldsymbol{B}$ & $\boldsymbol{M O}$ \\
\hline Freundlich & $\mathrm{K}_{F}\left(\mathrm{~L} \mathrm{~g}^{-1}\right)$ & 3.80 & 1.79 \\
& $1 / \mathrm{n}$ & 0.1892 & 0.2785 \\
& $\mathrm{R}^{2}$ & 0.9771 & 0.9715 \\
Langmuir & $\mathrm{q}_{\mathrm{m}}\left(\mathrm{mg} \mathrm{g}^{-1}\right)$ & 11.03 & 8.91 \\
& $\left.\mathrm{~b}(\mathrm{~L} \mathrm{mg})^{-1}\right)$ & 0.078 & 0.038 \\
& $\mathrm{R}^{2}$ & 0.9986 & 0.9986 \\
\hline
\end{tabular}

$\mathrm{K}_{\mathrm{F}}$ : constant in Freundlich model $\left(\mathrm{mg} \mathrm{g}^{-1}\right)\left(\mathrm{L} \mathrm{mg}^{-1}\right)^{1 / \mathrm{n}} ; 1 / \mathrm{n}$ : Freundlich power constant; $\mathrm{g}_{\mathrm{m}}$ : monolayer adsorption capacity $\left(\mathrm{mg} \mathrm{g}^{-1}\right)$; b: constant in Langmuir isotherm model $\left(\mathrm{L} \mathrm{mg}^{-1}\right)$.

Table 2. Comparison of adsorption capacities of various composite adsorbents for the removal of MB and MO dyes

\begin{tabular}{|c|c|c|}
\hline Composite Adsorbents (Pollutants) & $\mathrm{q}_{\mathrm{m}}\left(\mathrm{mg} \mathrm{g}^{-1}\right)$ & Reference \\
\hline Composite gel bead (MB) & 4.85 & {$[10]$} \\
\hline $\mathrm{NiO} / \mathrm{MCM}-41$ composite (MB) & 24.40 & {$[11]$} \\
\hline $\mathrm{CMC} / \mathrm{kC} / \mathrm{AMMT}$ composite bead (MB) & 10.75 & {$[12]$} \\
\hline $\mathrm{Fe} / \mathrm{GBHC}$ composite $(\mathrm{MB})$ & 11.03 & This work \\
\hline Chitosan/organic rectorite composite (MO) & 5.56 & [13] \\
\hline $\mathrm{Fe}_{2} \mathrm{O}_{3} / \mathrm{SiO}_{2} /$ chitosan nanocomposite (MO) & 34.29 & {$[14]$} \\
\hline Alginate/polyaspartate hydrogel composite (MO) & $0.22-0.28$ & [15] \\
\hline $\mathrm{Fe} / \mathrm{GBHC}$ composite (MO) & 8.91 & This work \\
\hline
\end{tabular}

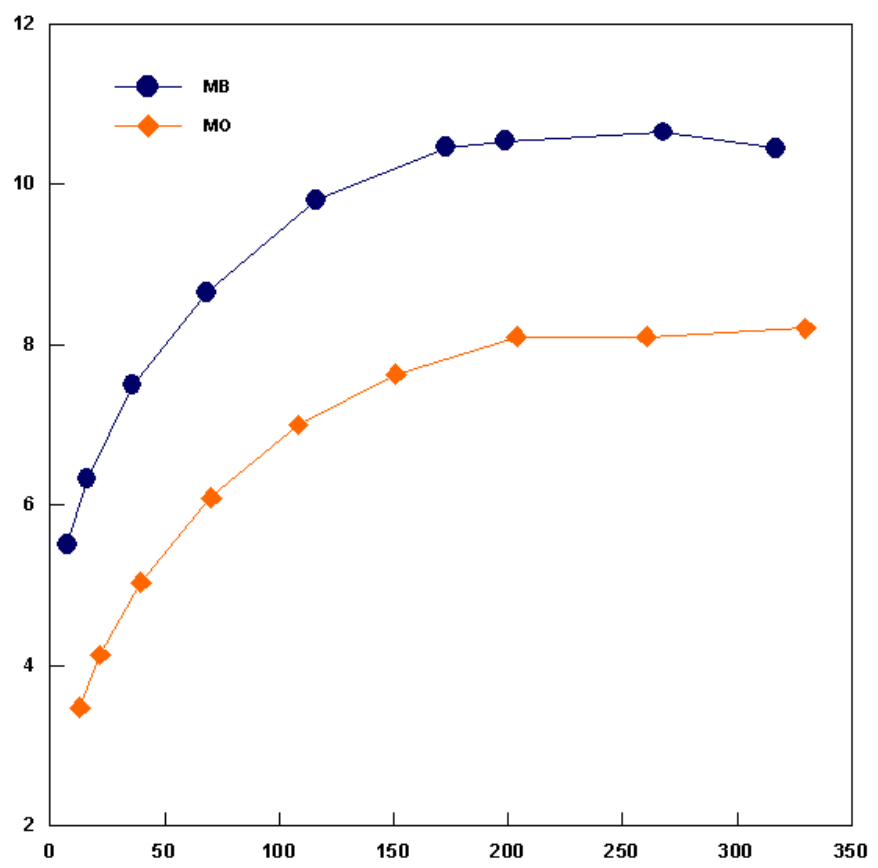

Figure 1. Adsorption isotherms of $\mathrm{MB}$ and $\mathrm{MO}$ onto $\mathrm{Fe} / \mathrm{GBHC}$ 


\section{Conclusions}

The new Fe/GBHC composite was successfully synthesized from GB by hydrothermal method in a single step. Fe/GBHC has shown good environmental performance. The maximum adsorption capacities for $\mathrm{MB}$ and $\mathrm{MO}$ were 11 and $8.9 \mathrm{mg} / \mathrm{g}$, respectively. Both equilibrium adsorption data agreed well with the Langmuir model. In summary, Fe/GBHC has great potential as an alternative adsorbent.

\section{References}

[1] González-García P. Activated carbon from lignocellulosics precursors: a review of the synthesis methods, characterization techniques and applications. Renew Sustain Energy Rev 2018;82:1393-1414.

[2] Robati D, Mirza B, Ghazisaeidi R, Rajabi M, Moradi O, Tyagi I, Agarwal S, Gupta VK. Adsorption behavior of methylene blue dye on nanocomposite multiwalled carbon nanotube functionalized thiol (MWCNT-SH) as new adsorbent. J Mol Liq 2016;216:83035.

[3] Park C, Lee M, Lee B, Kim SW, Chase HA, Lee J, Kim S. Biodegradation and biosorption for decolorization of synthetic dyes by Funalia trogii. Biochem Eng J 2007;36:59-65.

[4] Wu Y, Su M, Chen J, Xu Z, Tang J, Chang X, Chen D. Superior adsorption of methyl orange by h- $\mathrm{MoS}_{2}$ microspheres: Isotherm, kinetics, and thermodynamic studies. Dyes Pigm 2019;170:107591-598.

[5] Shi W, Song S, Zhang H. Hydrothermal synthetic strategies of inorganic semiconducting nanostructures. Chem Soc Rev 2013;42(13):5714-43.

[6] Hang Y, Si Y, Zhou Q, Yin H, Wang A, Cao A. Morphology-controlled synthesis of calcium titanate particles and adsorption kinetics, isotherms, and thermodynamics of $\mathrm{Cd}(\mathrm{II}), \mathrm{Pb}(\mathrm{II})$, and Cu (II) cations. J Hazard Mater 2019;380:120789-120802.

[7] Gai C, Zhang F, Lang Q, Liu T, Peng N, Liu Z. Facile one-pot synthesis of iron nanoparticles immobilized into the porous hydrochar for catalytic decomposition of phenol. Appl Catal B 2017;204:566-76.

[8] Freundlich HMF. Over the adsorption in solution. J Phys Chem A 1906;57:385-470.

[9] Langmuir I. The constitution and fundamental properties of solids and liquids. J Am Chem Soc 1916;38:2221-95.

[10] Jabli M, Hassine BB. Improved removal of dyes by [sodium alginate/4-methyl-2(naphthalen2-yl)-N-propylpentanamide-functionalized ethoxy-silica] composite gel beads. Int J Biol Macromol 2018;117:247-55.

[11] Xiao X, Zhang F, Feng Z, Deng S, Wang Y. Adsorptive removal and kinetics of methylene blue from aqueous solution using NiO/MCM-41 composite. Physica E Low Dimens Syst Nanostruct 2015;65:4-12.

[12] Liu C, Omer AM, Ouyang X-k. Adsorptive removal of cationic methylene blue dye using carboxymethyl cellulose/k-carrageenan/activated montmorillonite composite beads: Isotherm and kinetic studies. Int J Biol Macromol 2018;106:823-33.

[13] Zeng L, Xie M, Zhang Q, Kang Y, Guo X, Xiao H, Peng Y, Luo J. Chitosan/organic rectorite composite for the magnetic uptake of methylene blue and methyl orange. Carbohydr Polym 2015;123:89-98. 
[14] Zhu H, Jiang R, Fu Y-Q, Jiang J-H, Xiao L, Zeng G-M. Preparation, characterization and dye adsorption properties of $\gamma-\mathrm{Fe}_{2} \mathrm{O}_{3} / \mathrm{SiO}_{2} /$ chitosan composite. Appl Surf Sci 2011;82:1337-44.

[15] Jeon YS, Lei J, Kim J-H. Dye adsorption characteristics of alginate/polyaspartate hydrogels. J Ind Eng Chem 2008;14:726-31. 